\title{
Temporal Dynamics and Resource Availability for Drosophilid Fruit Flies (Insecta, Diptera) in a Gallery Forest in the Brazilian Savanna
}

\author{
Henrique Valadão, ${ }^{1}$ John Du Vall Hay, ${ }^{2}$ and Rosana Tidon ${ }^{3}$ \\ ${ }^{1}$ Programa de Pós Graduação em Ecologia, Instituto de Biologia, Universidade de Brasília, \\ Campus Universitário Darcy Ribeiro, Asa Norte, 70910-900 Brasília, DF, Brazil \\ ${ }^{2}$ Departamento de Ecologia, Instituto de Biologia, Universidade de Brasília, Campus Universitário Darcy Ribeiro, \\ Asa Norte, 70910-900 Brasília, DF, Brazil \\ ${ }^{3}$ Departamento de Genética, Instituto de Ciências Biologicas-GEM, Universidade de Brasília, CP 04457, \\ 70919-970 Brasilia, DF, Brazil
}

Correspondence should be addressed to Rosana Tidon, rotidon@unb.br

Received 26 February 2010; Accepted 22 July 2010

Academic Editor: Panos V. Petrakis

Copyright (C) 2010 Henrique Valadão et al. This is an open access article distributed under the Creative Commons Attribution License, which permits unrestricted use, distribution, and reproduction in any medium, provided the original work is properly cited.

\begin{abstract}
Seasonality can cause severe bottlenecks in natural populations, even leading to local extinction. Large variation in resource availability may explain the bottlenecks, but the role of these variations is still poorly understood. The goal of this study was to analyze if temporal variations in the guild of drosophilids breeding in fruits of Mauritia flexuosa (Arecaceae) can be explained by the shortage of this resource during the dry season. Fruits of $M$. flexuosa were collected over one year in a gallery forest located in the Central Brazilian Savanna. The drosophilid assemblage varied over time, with a lower density of species and of individuals in the dry season, when the percentage of colonized fruits was also smaller. These findings suggest that although the fruits were available during the dry season, they were underused. This way, the resource availability does not seem to regulate the community in the dry season.
\end{abstract}

\section{Introduction}

The dynamics of communities varies in space and time and is strongly influenced by environmental heterogeneity $[1,2]$. Changes in temperature, humidity, and resource availability, among other factors, can change the size, density, and distribution of populations. Part of these changes has evolutionary meaning, since they affect the structure and genetic composition of populations [3]. However, although the relationships between organisms and environments have been a central issue in ecology, they are still poorly known [4].

Seasonal variations, common in nature, may impose stressful conditions on individuals and limit the growth of populations, especially in insect communities [5]. Fluctuations in temperature and water availability may impose physiological constraints [6] and change the availability of resources necessary for growth and reproduction of individuals [7-9]. Additionally, biological interactions with the potential to regulate populations, such as competition, parasitism, and predation, also may change according to season [10]. Given that communities have different responses to environmental seasonality, the knowledge of how these seasonal patterns affect populations is fundamental to understand the interactions between species.

The decrease of food resources experienced by populations during the stressful season reduces the amount of energy available for individual growth and reproduction $[11,12]$ and thus may limit the population growth [13] or even lead to local extinction [14]. However, if a small 
portion of resource is available during stressful seasons, this could serve as a refuge for the maintenance of populations that depend on it. In fact, some insects have their life histories governed by the cycles of abundance of food resources [15]. If the population size is regulated only by the availability of resources, then we can expect population increase in favorable seasons, when resources are abundant, and decrease during the stressful season, when resources are scarce. In line with this scenario, Campos et al. [16] predicted that, under stressful conditions, ephemeral resources that are occasionally available will be intensively used.

The Brazilian Savanna, characterized by the alternation of dry and rainy seasons [17], is a good area to study effects of seasonality. This area, known as Cerrado, is the largest savanna in a single country, covering approximately 2 million $\mathrm{km}^{2}$ [18]. It is considered a biodiversity hotspot, having high endemism and a high level of degradation, with more than $60 \%$ of its native vegetation destroyed, mainly due to human activities [19]. The rainy season is from October to March, and the dry season is from April to September, with an average annual rainfall of $1500 \mathrm{~mm}$ [20], but rain rarely occurs in the dry season.

Species in the family Drosophilidae are excellent biological models in studies of genetics and evolution, but still relatively little used to investigate ecological issues [21]. Drosophilids feed on microorganisms present in biological materials in decomposition, such as fallen fruits and flowers, fungi and others, and their abundance shows a marked seasonal variation $[1,22,23]$. In the Cerrado, the populations expand during the rainy season and strongly reduce in the dry season, but the reasons for such fluctuations are not well understood [24]. It is known that the cycles of drosophilid populations are fairly well explained by climatic factors such as temperature and humidity [24-26], but there are few studies focusing on the relationship between the availability of resources and population size of these flies [1, 27, 28]. Studies under this perspective would be of great contribution to the understanding of the mechanisms responsible for seasonal variations of these insects.

In the Cerrado, there are a large number of plant species that produce fleshy fruits, ideal as breeding sites of drosophilids, and these are dispersed during the rainy season [29], when the peak population of drosophilids is recorded. In the dry season, when the populations are constricted, relatively few food resources can be found. This study characterized a drosophilid assembly associated with fruits of the palm Mauritia flexuosa (Arecaceae) during one year, in order to investigate whether the lack of resources for larval growth (breeding sites) that characterizes the dry season could explain the population bottleneck of flies in this season. This hypothesis generates the following predictions: (1) the species density of drosophilid during the dry season is lower than in the rainy season, due the resource scarcity, and (2) the individual density on the fruits and the percentage of colonized fruits are higher in the dry season, since the individuals aggregate on the few fruits available in this season.

\section{Methods}

2.1. Area of Study. The collections were carried in the Ecological Reserve of IBGE (Instituto Brasileiro de Geografia e Estatística)-RECOR $\left(15^{\circ} 56^{\prime} \mathrm{S}, 47^{\circ} 53^{\prime} \mathrm{W}\right)$, which is part of a continuous area of environmental protection of 10,000 ha of the Cerrado biome. We sampled fallen fruits from six palm trees located in a flooded gallery forest, where fallen fruits were collected monthly between May 2006 and April 2007.

2.2. Plant Species. Mauritia flexuosa L. f., commonly known as buriti, is a Neotropical palm widely distributed throughout South America. It is a hygrophytic species that occurs grouped in permanently flooded areas. The fruit is a berry and is an ellipsoid in shape, about five centimeters in length. Although the fruit production is more intense between December and June [30], it is common to find trees with fruit throughout the year. There is a rich fauna of arthropods associated with the canopy [31], and buriti fruits are one of the few resources available for drosophilids during the dry season.

2.3. Collections and Identification. During the peak of the dry season (May to August 2006), period of low availability of fruits, all fruits were collected. After this period, about 10 fruits of each palm were collected randomly, due to the high abundance of these. Although the palms were in a flooded area, none of the fruits collected in the rainy season were covered, partially or completely, by water. All palms were no more than $50 \mathrm{~m}$ apart from each other. The collected fruits were placed in plastic bags and taken to the laboratory. Then, they were individually maintained on wet sand with a solution of Nipagin (a preservative fungicide), in plastic containers covered with a piece of cloth. There were no large visible variations in size and weight of the collected fruits. A piece of wet cotton was placed on the cloth in order to avoid low humidity. All adults that emerged were removed every other day and identified at the species level using external morphology $[32,33]$ and/or analysis of male terminalia $[34,35]$. All adults were deposited in the collection of the Laboratorio de Biologia Evolutiva of the Universidade de Brasília.

2.4. Analysis of the Assembly. Patterns of dominance of species in the community over all collections were inferred by a rank-abundance plot. The proportion of neotropical and exotic (non-neotropical) species was examined monthly, in order to verify changes in the composition of these two categories. Differences in species density between the nuclear dry (June, July, and August) and rainy (December, January, and February) seasons were evaluated using sample-based rarefaction curves (EstimateS 7.5, [36]), considering each fruit as a sample. Rarefaction curves were used to compare differences between the density of species, which is the number of species per unit of fruit, rather than the richness itself [37]. A Mann-Whitney test was used to determine if population densities (average number of flies per fruit) between the dry and rainy seasons were statistically different. 


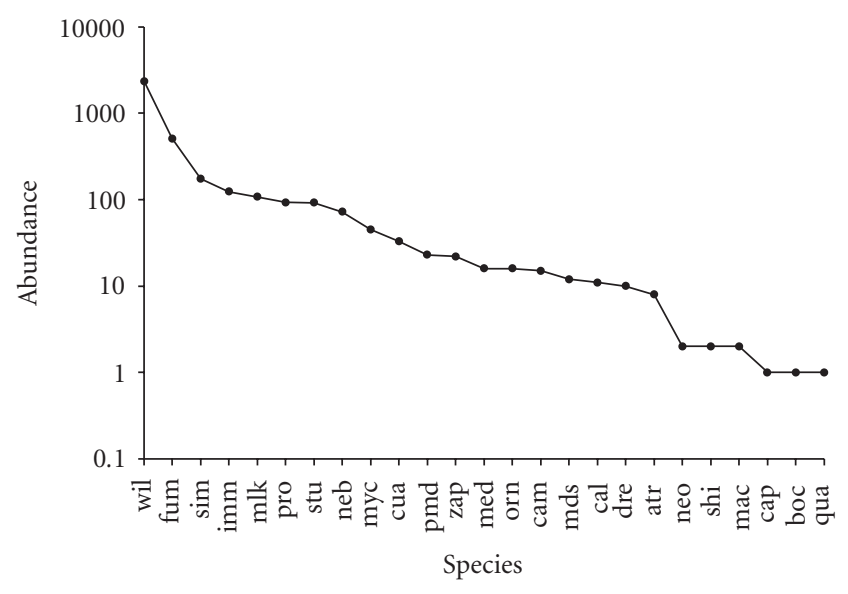

Figure 1: Absolute abundance of drosophilid species breeding in Mauritia flexuosa fruits in a gallery forest of the Ecological Reserve of IBGE, Brasília, DF. wil: Drosophila willistoni, fum: D. fumipennis, sim: D. simulans, imm: D. immigrans, mlk: D. malerkotliana, pro: D. prosaltans, stu: D. stutervanti, neb: D. nebulosa, myc: Mycodrosophila sp., cua: D. cuaso, pmd: D. paramediostriata, zap: Zaprionus indianus, med: D. mediostriata, orn: D. ornatifrons, cam: D. camargoi, mds: D. mediosignata, cal: D. calloptera, dre: $D$. dreyfusi, atr: D. atrata, neo: Neotanigastrela tricoloripes, shi: $D$. shildi, mac: $D$. maculifrons, cap: $D$. capricorni, boc: $D$. bocainensis, qua: D. quadrum.

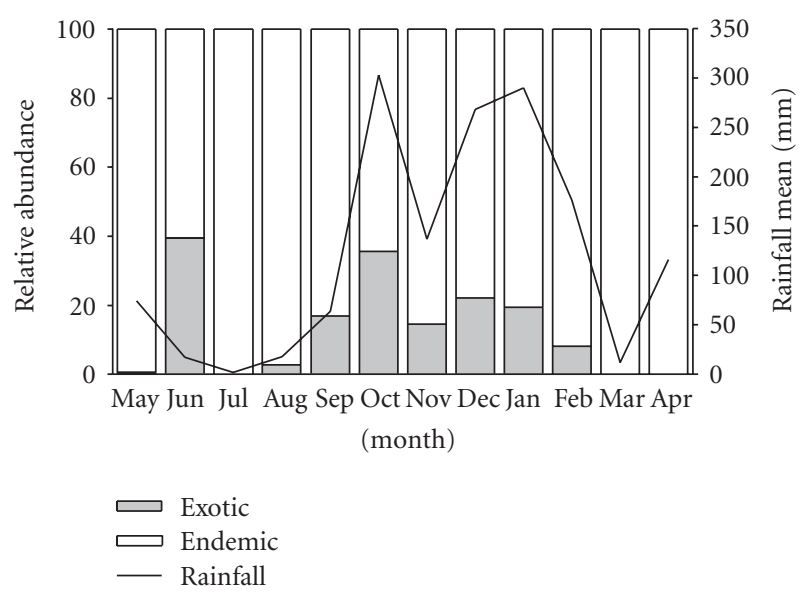

FIGURE 2: Temporal variation in rainfall and in the proportion (\%) of neotropical and exotic drosophilids in fruits of Mauritia flexuosa collected in a gallery forest of the Ecological Reserve of IBGE, Brasília, DF.

A Comparative Binomial Trial [38] was used to determine if the proportion of fruits colonized (resource saturation) was different between the two seasons. Spearman's correlation coefficient was used to investigate if population density was related to the resource saturation. The statistic tests were performed on BioEstat 5.0 software [39].

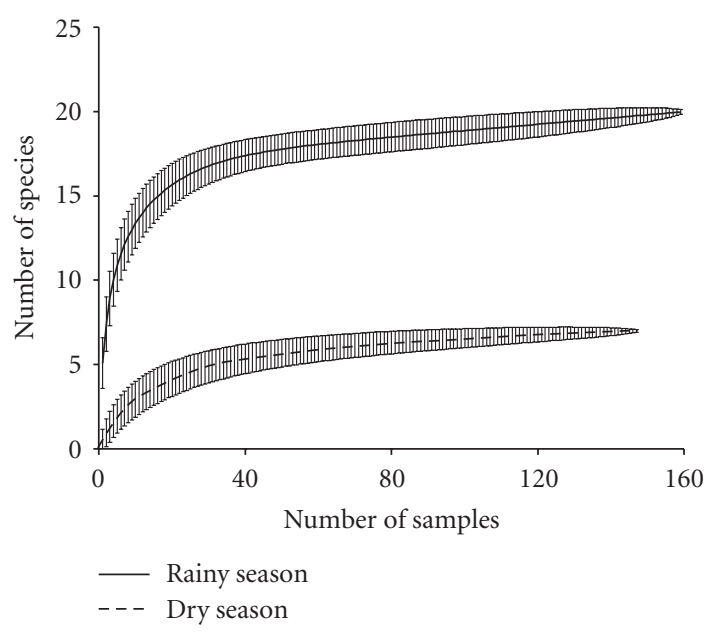

FIGURE 3: Density species showed by rarefaction curves (samplebased) of drosophilid species reared in Mauritia flexuosa collected in a gallery forest of the Ecological Reserve of IBGE, Brasília, DF during the dry season (June, July and August, $n=148$ ) and the rainy season (December, January and February, $n=160$ ). Error bars represent standard deviation.

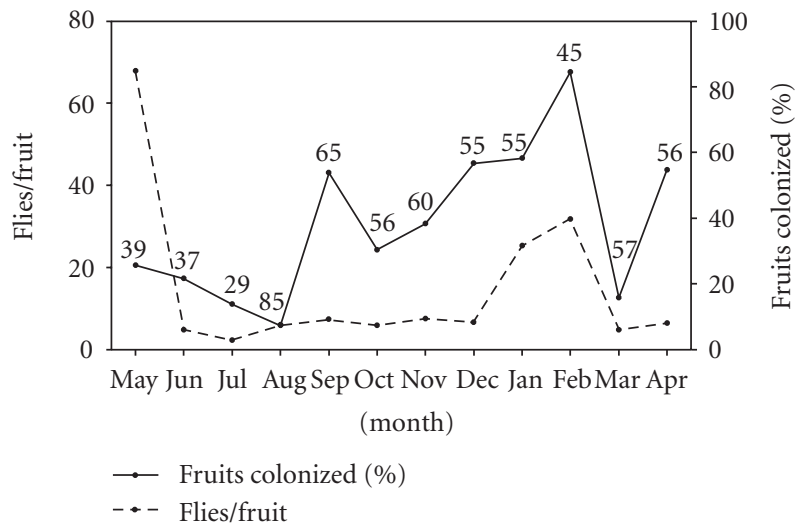

FIGURE 4: Use of Mauritia flexuosa by drosophilids from May 2006 to April 2007 collected in a gallery forest of the Ecological Reserve of IBGE, Brasília, DF. The dotted line represents the mean number of flies per fruit, and the continuous line the percentage of colonized fruits. Values above the continuous line refer to the total fruits in each month.

\section{Results}

We collected 638 fruits, 245 of these fruits were colonized by flies from the family Drosophilidae. We obtained a total of 3763 individual flies belonging to 27 species distributed over four genera (Table 1). The abundance varied among species (Figure 1) with a strong dominance of two closely related Neotropical species: Drosophila willistoni and Drosophila fumipennis. The four exotic species recorded, two from Africa (Drosophila simulans and Zaprionus indianus) and two from the Oriental region (Drosophila immigrans and Drosophila malerkotliana), accounted for $11.4 \%$ of the entire sample. The percentage of exotic species in each sample varied during the year from zero to $40 \%$ (Figure 2). Among 
TABLE 1: Abundance of drosophilids species breeding in Mauritia flexuosa fruits collected in a gallery forest of the Ecological Reserve of IBGE, Brasília, DF. Rainy season: October to March, dry season: April to September.

\begin{tabular}{|c|c|c|c|}
\hline Taxon & Rainy & Dry & Total \\
\hline Drosophila willistoni Sturtevant, 1916 & 1466 & 885 & 2351 \\
\hline D. fumipennis Duda, 1925 & 373 & 134 & 507 \\
\hline D. simulans ${ }^{\dagger}$ Sturtevant, 1919 & 154 & 20 & 174 \\
\hline D. immigrans ${ }^{\dagger}$ Sturtevant, 1921 & 86 & 38 & 124 \\
\hline D. malerkotliana ${ }^{\dagger}$ Parshad and Paika, 1964 & 104 & 4 & 108 \\
\hline D. prosaltans Duda, 1927 & 69 & 24 & 93 \\
\hline D. stutervanti Duda, 1927 & 87 & 5 & 92 \\
\hline D. nebulosa Sturtevant, 1916 & 65 & 7 & 72 \\
\hline Mycodrosophila sp. 1 & 41 & 4 & 45 \\
\hline D. cuaso Bächli, Vilela and Ratcov, 2000 & 16 & 17 & 33 \\
\hline D. paramediostriata Townsend and Wheeler, 1955 & 0 & 23 & 23 \\
\hline Zaprionus indianus ${ }^{\dagger}$ Gupta, 1970 & 22 & 0 & 22 \\
\hline D. mediostriata Duda, 1925 & 14 & 2 & 16 \\
\hline D. ornatifrons Duda, 1927 & 11 & 5 & 16 \\
\hline D. camargo $^{\ddagger}$ Dobzhansky and Pavan in Pavan, 1950 & 14 & 1 & 15 \\
\hline D. mediosignata Dobzhansky and Pavan, 1943 & 2 & 10 & 12 \\
\hline D. calloptera Schiner, 1868 & 11 & 0 & 11 \\
\hline D. dreyfusi Dobzhansky and Pavan, 1943 & 10 & 0 & 10 \\
\hline D. atrata Burla and Pavan, 1953 & 7 & 1 & 8 \\
\hline Neotanygastrela tricoloripes ${ }^{\ddagger}$ Duda, 1925 & 0 & 2 & 2 \\
\hline D. schildi Malloch, 1924 & 0 & 2 & 2 \\
\hline D. maculifrons Duda, 1927 & 1 & 1 & 2 \\
\hline D. capricorni Dobzhansky and Pavan, 1943 & 1 & 0 & 1 \\
\hline D. bocainensis Pavan and da Cunha, 1947 & 0 & 1 & 1 \\
\hline D. quadrum ${ }^{\ddagger}$ Wiedemann, 1830 & 1 & 0 & 1 \\
\hline Drosophila sp. 1 & 0 & 8 & 8 \\
\hline Drosophila sp. 2 & 10 & 4 & 14 \\
\hline
\end{tabular}

${ }^{\dagger}$ Exotic species.

${ }^{\ddagger}$ New record for the Cerrado biome.

the 27 species collected, three are new records for the Cerrado biome: Drosophila camargoi, Drosophila quadrum, and Neotanygastrella tricoloripes. Both rarefaction curves came close to an asymptote, with a few species included after 50 samples for both seasons (dry and wet). Species density was lower during the dry season (Figure 3 ), as well as the population density in fruits $\left(U=5095.00, P<.001, N_{1}=\right.$ $148, N_{2}=160$ ). Drosophilid resource use varied over time, with a smaller proportion of colonized fruits during the dry season $\left(\chi^{2}=87.54, P<.0001, d f=1\right)$. The percentage of fruits colonized was positively correlated with fly density $\left(r_{s}\right.$ $=0.860, P<.05, d f=11$ ) (Figure 4).

\section{Discussion}

Mauritia flexuosa demonstrated a large drosophilid abundance compared to other breeding sites within the Brazilian Savanna [40-43]. The assemblage is characterized by two dominant species (D. willistoni and D. fumipennis), which comprised about $76 \%$ of the sampled individuals. These two Neotropical forest species are collected throughout Brazil $[24,44,45]$. In contrast, 17 species were rare with each species contributing less than $1 \%$ and totaling $5 \%$ of the entire sample (Figure 1, Table 1). Three rare species belonging to the genera Drosophila Fallén and Neotanygastrella Duda are new records for Cerrado. These results indicate that drosophilid assemblages are still undersampled in this biome, highlighting the need for more inventories [43].

An interesting result was the low frequency and richness of exotic species. We only recorded four species, even though their frequencies varied throughout the year, they never exceeded $40 \%$ of the total for any given month (Figure 2). This result contradicts previous studies in the Cerrado, where exotic species usually are dominant in the assemblages during the dry season and the beginning of the rainy season sometimes exceeding $90 \%$ of the sample $[24,46]$.

Our results support the prediction that species density is lower in the dry season (Figure 3). Variation in species density under different environmental conditions has been observed for several groups of flies [47, 48], beetles [49, 50], and ants, in which variation in species density (and richness) appears to be caused by a combination of environmental stress and competition [51]. In Cerrado, the dry season imposes strong environmental stress for the majority of 
insects, with temperature and humidity below their optimum $[24,25,52]$. As tropical drosophilids probably average more than one generation a month (most species reach sexual maturity within two days and begin to lay eggs around the third day), in a few months they can show short-term temporal changes caused by stronger selective pressures, with few species generating offspring.

During the dry season, both the density of drosophilids in the fruits and the proportion of fruits colonized were lower than in the rainy season (Figure 4). These results suggest that fruits were used less in the dry season, refuting the hypothesis that the scarcity of resources characteristic of this period explains the population bottleneck of flies in this season. It is possible that the populations of flies are regulated by abiotic factors such as temperature and humidity. Additionally, since few Cerrado plant species disperse their fruits in the dry season [29], it is still possible that the decrease in fly population during this period is due to an overall decrease in the amount of resources as a whole. Therefore, M. flexuosa would play an important role in the life history of these insects, maintaining the populations, even at low densities, during the stressful season.

Another possible explanation for the low density of drosophilids during the dry season is that fruit quality may vary throughout time, changing their quality as a resource. It is important to consider that the seasonality of the Cerrado biome can change the composition of fruits, especially the amount of water and sugars. Consequently, the microbial decomposers, which serve as food for the fly larvae, may also change reflecting changes in the drosophilid populations. The amount of lipids is a good indicator of fruit quality and quantity and they vary throughout the year in Neotropical fruits, tending to be in greater concentrations during the rainy seasons [53]. Therefore, even if the fruits are available during the dry season, the stressful time of the year, their nutritional value can be compromised to the point where they can not maintain the population and, thus, are not considered an available resource. The components necessary for the full development of individuals, such as the breeding resource (the fruits) and the food resource (the microorganisms) should be available at the same time and the same place.

In summary, our study shows that the palm Mauritia flexuosa maintains a rich drosophilid fauna [42, 54-57], with a predominance of Neotropical species including some previously unrecorded species in the Cerrado. Moreover, it provides some new information about the species-resource relationship. As we predicted, there is a reduction in species density during the dry season. Since all species are in low numbers and the environmental conditions are below the optimum for these species, this reduction may be caused by a stronger selective pressure. The reduction in the percentage of fruits used and in the density of individual flies during the dry season suggests that the populations are not regulated by the availability of fruit, but by other mechanisms. Studies aimed to investigate the variation in the quality of the fruit throughout the year and the intrinsic characteristics of species, such as diapause, are needed to improve the understanding of these assemblages' temporal dynamics.

\section{Acknowledgments}

The authors are grateful to A. Brito for helping in the field work. They are also grateful to Universidade de Brasília and Reserva Ecológica do IBGE for logistical support. This work received financial support from the Conselho Nacional de Desenvolvimento Científico e Tecnológico $(\mathrm{CNPq})$ and PRONEX-FAP/DF.

\section{References}

[1] T. Dobzhansky and C. Pavan, "Local and seasonal variations in relative frequencies of species of Drosophila in Brazil," Journal of Animal Ecology, vol. 19, no. 1, pp. 1-14, 1950.

[2] H. Wolda, "Fluctuations in abundance of tropical insects," American Naturalist, vol. 112, no. 988, pp. 1017-1045, 1978.

[3] O. Savolainen, T. Pyhäjärvi, and T. Knürr, "Gene flow and local adaptation in trees," Annual Review of Ecology, Evolution, and Systematics, vol. 38, pp. 595-619, 2007.

[4] M. Begon, C. R. Townsend, and J. L. Harper, Ecology: From Individuals to Ecosystems, Blackwell, Oxford, UK, 4th edition, 2006.

[5] H. Wolda, "Insect seasonality-why?" Annual Review of Ecology and Systematics, vol. 19, pp. 1-18, 1988.

[6] K. Bowler and J. S. Terblanche, "Insect thermal tolerance: what is the role of ontogeny, ageing and senescence?" Biological Reviews, vol. 83, no. 3, pp. 339-355, 2008.

[7] C. P. van Schaik, J. W. Terborgh, and S. J. Wright, "The phenology of tropical forests-adaptive significance and consequences for primary consumers," Annual Review of Ecology and Systematics, vol. 24, pp. 353-377, 1993.

[8] J. Hone and T. H. Clutton-Brock, "Climate, food, density and wildlife population growth rate," Journal of Animal Ecology, vol. 76, no. 2, pp. 361-367, 2007.

[9] S. E. Williams and J. Middleton, "Climatic seasonality, resource bottlenecks, and abundance of rainforest birds: implications for global climate change," Diversity and Distributions, vol. 14, no. 1, pp. 69-77, 2008.

[10] K. E. Veblen, "Season-and herbivore-dependent competition and facilitation in a semiarid savanna," Ecology, vol. 89, no. 6, pp. 1532-1540, 2008.

[11] D. L. Denlinger, "Seasonal and annual variation of insect abundance in the Nairobi-National-Park, Kenya," Biotropica, vol. 12, no. 2, pp. 100-106, 1980.

[12] E. G. Martins, V. Bonato, C. Q. da-Silva, and S. F. dos Reis, "Seasonality in reproduction, age structure and density of the gracile mouse opossum Gracilinanus microtarsus (Marsupialia: Didelphidae) in a Brazilian cerrado," Journal of Tropical Ecology, vol. 22, no. 4, pp. 461-468, 2006.

[13] F. Pinheiro, I. R. Diniz, D. Coelho, and M. P. S. Bandeira, "Seasonal pattern of insect abundance in the Brazilian cerrado," Austral Ecology, vol. 27, no. 2, pp. 132-136, 2002.

[14] H. J. De Boeck, A. Visscher, A. Milbau, and I. Nijs, "Quantifying the randomness of extinctions," Ecography, vol. 31, no. 3, pp. 327-334, 2008.

[15] M. F. Braby, "Reproductive seasonality in tropical satyrine butterflies: strategies for the dry season," Ecological Entomology, vol. 20, no. 1, pp. 5-17, 1995.

[16] W. G. Campos, J. H. Schoereder, and O. F. DeSouza, "Seasonality in neotropical populations of Plutella xylostella (Lepidoptera): resource availability and migration," Population Ecology, vol. 48, no. 2, pp. 151-158, 2006. 
[17] G. Eiten, "The cerrado vegetation of Brazil," The Botanical Review, vol. 38, no. 2, pp. 201-341, 1972.

[18] P. S. Oliveira and R. J. Marquis, Marquis, The Cerrados of Brazil: Ecology and Natural Hhistory of Neotropical Savanna, Columbia University Press, New York, NY, USA, 2002.

[19] N. Myers, R. A. Mittermeler, C. G. Mittermeler, G. A. B. da Fonseca, and J. Kent, "Biodiversity hotspots for conservation priorities," Nature, vol. 403, no. 6772, pp. 853-858, 2000.

[20] J. A. Ratter, J. F. Ribeiro, and S. Bridgewater, "The Brazilian cerrado vegetation and threats to its biodiversity," Annals of Botany, vol. 80, no. 3, pp. 223-230, 1997.

[21] J. R. Powell, Progress and Prospects in Evolutionary Biology: The Drosophila Model, Oxford University Press, Oxford, UK, 1997.

[22] J. S. F. Barker, R. A. Krebs, and H. I. Davies, "Geographical distributions, relative abundance and coexistence of Drosophila aldrichi and Drosophila buzzatii in Australia," Austral Ecology, vol. 30, no. 5, pp. 546-557, 2005.

[23] M. Kondo and M. T. Kimura, "Diversity of drosophilid flies on Kume-jima, a subtropical island: comparison with diversity on Iriomote-jima," Entomological Science, vol. 11, no. 1, pp. 7-15, 2008.

[24] R. Tidon, "Relationships between drosophilids (Diptera, Drosophilidae) and the environment in two contrasting tropical vegetations," Biological Journal of the Linnean Society, vol. 87, no. 2, pp. 233-247, 2006.

[25] J. R. David, R. Allemand, J. van Herrewege, and Y. Cohet, "Ecophysiology: abiotic factors," in Genetics and Biology of Drosophila, M. Ashburner, H. Carson, and J. N. Thompson, Eds., pp. 105-170, Academic Press, New York, NY, USA, 1983.

[26] G. W. Gilchrist, R. B. Huey, and L. Partridge, "Thermal sensitivity of Drosophila melanogaster: evolutionary responses of adults and eggs to laboratory natural selection at different temperatures," Physiological Zoology, vol. 70, no. 4, pp. 403 414, 1997.

[27] C. M. Breitmeyer and T. A. Markow, "Resource availability and population size in cactophilic Drosophila," Functional Ecology, vol. 12, no. 1, pp. 14-21, 1998.

[28] E. M. Moraes and F. M. Sene, "Relationships between necrotic cactus availability and population size in a cactophilic Drosophila (Diptera, Drosophilidae) located on a sandstone table hill in Brazil," Revista de Biologia Tropical, vol. 51, no. 1, pp. 205-212, 2003.

[29] P. E. Oliveira, "Fenologia e biologia reprodutiva das espécies de Cerrado," in Cerrado: Ambiente e Flora, S. M. Sano and S. P. Almeida, Eds., pp. 169-192, Embrapa-CPAC, Planaltina, Brazil, 1998.

[30] S. P. Almeida, C. E. B. Proença, S. M. Sano, and J. F. Ribeiro, Cerrado: Espécies Vegetais Úteis, Embrapa-CPAC, Planaltina, Brazil, 1998.

[31] R. Gurgel-Gonçalves, A. R. T. Palma, P. C. Motta, M. E. Bar, and C. A. C. Cuba, "Arthropods associated with the crown of Mauritia flexuosa (Arecaceae) palm trees in three different environments from Brazilian Cerrado," Neotropical Entomology, vol. 35, no. 3, pp. 302-312, 2006.

[32] N. Freire-Maia and C. Pavan, "Introdução ao estudo da drosófila," Cultus, vol. 1, pp. 1-171, 1949.

[33] H. Burla and C. Pavan, "The 'calloptera' group of species (Drosophilidae, Diptera)," Revista Brasileira de Biologia, vol. 13, pp. 291-314, 1953.

[34] C. Malagolowkin, "Sobre a genitália dos Drosophilidae (Diptera). III. Grupo willistoni do gênero Drosophila," Revista Brasileira de Biologia, vol. 12, no. 1, pp. 79-96, 1952.

[35] C. R. Vilela and G. Bächli, "Taxonomic studies on Neotropical species of seven genera of Drosophilidae (Diptera),"
Mitteilungen der Schweizerischen Entomologischen Gesellschaft, vol. 63, pp. 1-332, 1990.

[36] R. K. Colwell, "EstimateS: statistical estimation of species richness and shared species from samples," User's Guide and application, 2005.

[37] N. J. Gotelli and R. K. Colwell, "Quantifying biodiversity: procedures and pitfalls in the measurement and comparison of species richness," Ecology Letters, vol. 4, no. 4, pp. 379-391, 2001.

[38] J. H. Zar, Biostatistical Analysis, Prentice Hall, Upper Saddler River, NJ, USA, 4th edition, 1999.

[39] M. Ayres, M. J. Ayres, D. L. Ayres, and A. A. S. Santos, BioEstat 5.0: Aplicações Estatísticas Nas Áreas de Ciências Biomédicas, Sociedade Civil de Miramauá, Belém, Brazil, 5th edition, 2007.

[40] C. R. Vilela, "Breeding sites of Neotropical Drosophilidae (Diptera). III. Rotting infructescences of Philodendron bipinnatifidum (Araceae)," Revista Brasileira de Entomologia, vol. 46, pp. 339-344, 2001.

[41] B. F. D. Leão and R. Tidon, "Newly invading species exploiting native host-plants: the case of the African Zaprionus indianus (Gupta) in the Brazilian Cerrado (Diptera, Drosophilidae)," Annales de la Societe Entomologique de France, vol. 40, no. 3-4, pp. 285-290, 2004.

[42] F. Roque, J. D. Hay, and R. Tidon, "Breeding sites of drosophilids (Diptera) in the Brazilian Savanna. I. Fallen fruits of Emmotum nitens (Icacinaceae), Hancornia speciosa (Apocynaceae) and Anacardium humile (Anacardiaceae)," Revista Brasileira de Entomologia, vol. 53, no. 2, pp. 308-313, 2009.

[43] N. B. Chaves and R. Tidon, "Biogeographical aspects of drosophilids (Diptera, Drosophilidae) of the Brazilian savanna," Revista Brasileira de Entomologia, vol. 52, no. 3, pp. 340-348, 2008.

[44] V. L. S. Valente and A. M. Araujo, "Chromosomal polymorphism, climatic factors, and variation in population size of Drosophila willistoni in southern Brazil," Heredity, vol. 57, pp. 149-159, 1986.

[45] D. C. de Toni, M. S. Gottschalk, J. Cordeiro, P. P. R. Hofmann, and V. L. S. Valente, "Study of the Drosophilidae (Diptera) communities on Atlantic forest islands of Santa Catarina state, Brazil," Neotropical Entomology, vol. 36, no. 3, pp. 356-375, 2007.

[46] R. Tidon, D. F. Leite, and B. F. D. Leão, "Impact of the colonisation of Zaprionus (Diptera, Drosophilidae) in different ecosystems of the neotropical region: 2 Years after the invasion," Biological Conservation, vol. 112, no. 3, pp. 299-305, 2003.

[47] M. Argemí, M. Monclús, F. Mestres, and L. Serra, "Comparative analysis of a community of Drosophilids (Drosophilidae; Diptera) sampled in two periods widely separated in time," Journal of Zoological Systematics and Evolutionary Research, vol. 37, no. 4, pp. 203-210, 1999.

[48] P. J. Folgarait, O. Bruzzone, S. D. Porter, M. A. Pesquero, and L. E. Gilbert, "Biogeography and macroecology of phorid flies that attack fire ants in south-eastern Brazil and Argentina," Journal of Biogeography, vol. 32, no. 2, pp. 353-367, 2005.

[49] T. O. Crist and R. G. Ahern, "Effects of habitat patch size and temperature on the distribution and abundance of ground beetles (Coleoptera: Carabidae) in an old field," Environmental Entomology, vol. 28, no. 4, pp. 681-689, 1999.

[50] A. Botes, M. A. McGeoch, and S. L. Chown, "Ground-dwelling beetle assemblages in the northern Cape Floristic Region: patterns, correlates and implications," Austral Ecology, vol. 32, no. 2, pp. 210-224, 2007. 
[51] C. L. Parr, B. J. Sinclair, A. N. Andersen, K. J. Gaston, and S. L. Chown, "Constraint and competition in assemblages: a cross-continental and modeling approach for ants," American Naturalist, vol. 165, no. 4, pp. 481-494, 2005.

[52] D. H. Janzen, "Sweep samples of tropical foliage insectseffects of seasons, vegetation types, elevation, time of day, and insularity," Ecology, vol. 54, no. 3, pp. 687-708, 1973.

[53] C. O. Worman and C. A. Chapman, "Seasonal variation in the quality of a tropical ripe fruit and the response of three frugivores," Journal of Tropical Ecology, vol. 21, no. 6, pp. 689697, 2005.

[54] W. D. Atkinson, "Coexistence of Australian rainforest Diptera breeding in fallen fruit," Journal of Animal Ecology, vol. 54, no. 2, pp. 507-518, 1985.

[55] H. Mitsui, K. H. Takahashi, and M. T. Kimura, "Spatial distributions and clutch sizes of Drosophila species ovipositing on cherry fruits of different stages," Population Ecology, vol. 48, no. 3, pp. 233-237, 2006.

[56] L. Nunney, "Drosophila on oranges: colonization, competition, and coexistence," Ecology, vol. 71, no. 5, pp. 1904-1915, 1990.

[57] J. G. Sevenster and J. J. M. van Alphen, "Aggregation and coexistence. II. A neotropical Drosophila community," Journal of Animal Ecology, vol. 65, no. 3, pp. 308-324, 1996. 

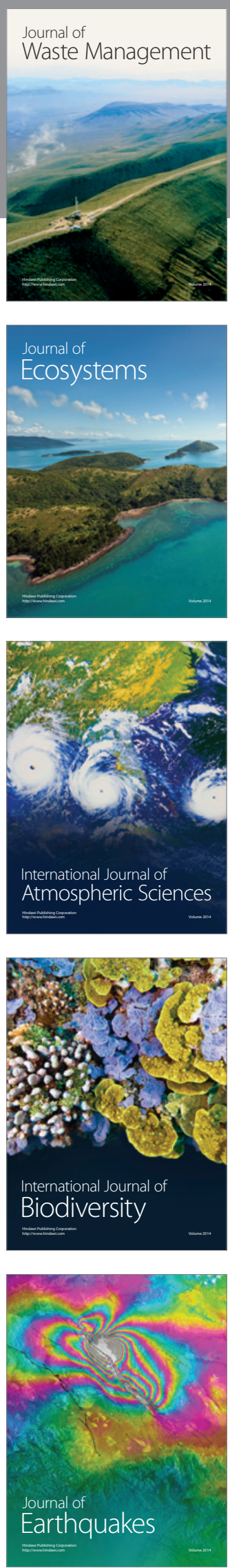
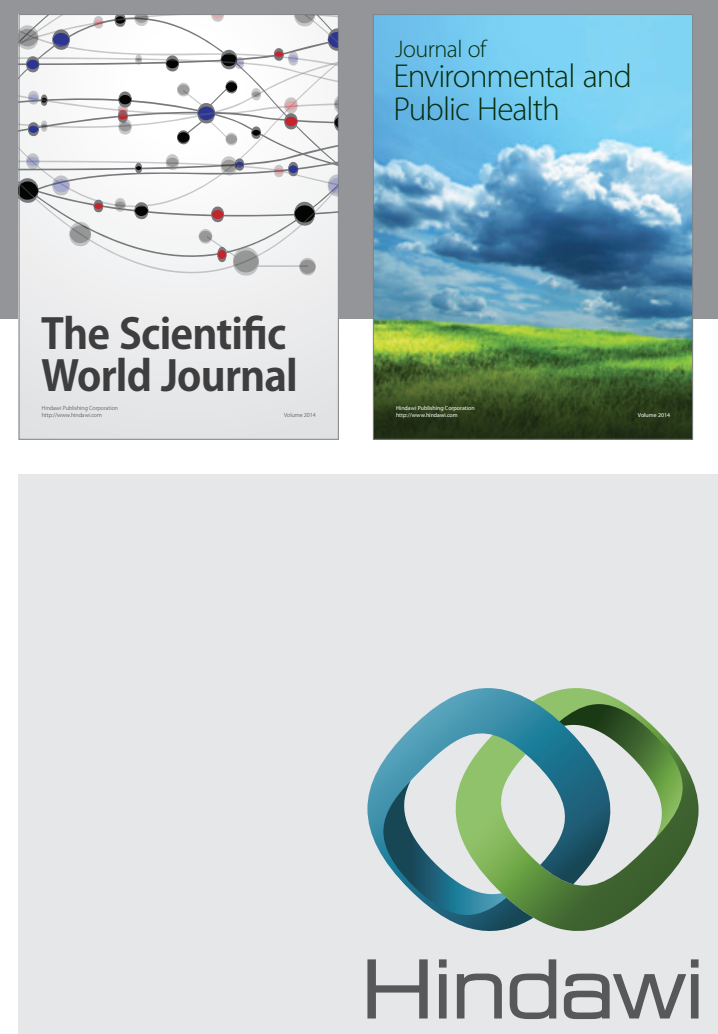

Submit your manuscripts at

http://www.hindawi.com
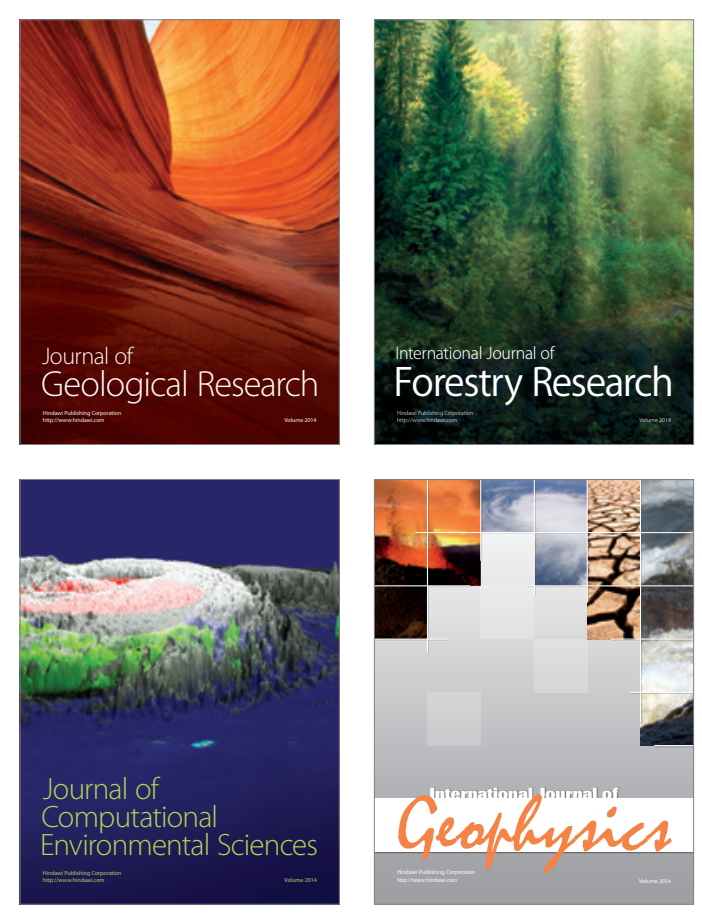
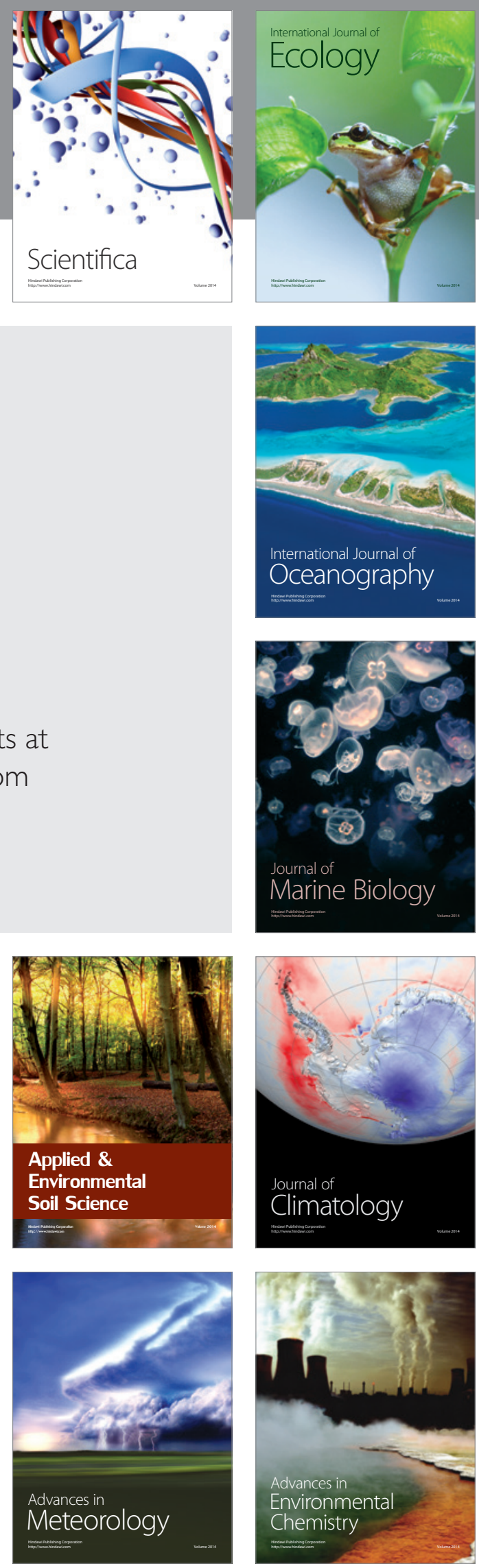